\title{
Teenagers' attitudes towards bicycle helmets three years after the introduction of mandatory wearing
}

\author{
Caroline F Finch
}

\begin{abstract}
Objectives and setting-To address helmet wearing by 13-17 year olds this study posed the following research questions: 'Do education programs continue to be necessary even after the community wearing rate has increased?' and 'Are helmet laws more effective in encouraging wearing among certain age groups?' Victoria was the first place in the world to introduce bicycle helmet legislation. Experiences in Victoria therefore provide a good model for the introduction of similar legislation in other areas. This study is the first to examine teenagers' attitudes towards helmet wearing after the introduction of compulsory helmet wearing legislation.
\end{abstract}

Methods-A survey of 1240 year 9 and year 10 students, aged 13-17 years, from 14 secondary schools in the outer south eastern suburbs of Melbourne, was conducted in September 1993. Information about bicycle use, helmet wearing, and attitudes towards helmets was obtained by a self report questionnaire.

Results-Bicycles are a popular form of wheeled recreation/self transport among teenagers. $65 \%$ of teenagers reported that they owned a helmet but only one third wore a helmet the last time they rode a bicycle. Fewer than $25 \%$ of students always wore a helmet when they rode a bicycle, despite compulsory helmet wearing legislation. Major factors leading to teenagers not wanting to wear a helmet were appearance and comfort. Both safety considerations and parental pressures were factors that influenced a teenager to wear a helmet.

Conclusions-The major areas that need to be addressed are low helmet wearing rates; the low priority given to safety issues compared with comfort and peer acceptance; an ignorance of the need for helmets in all riding situations; and a perception that the legislation would not be enforced.

(Injury Prevention 1996; 2: 126-130)

Keywords: bicycle helmets, attitudes, teenagers.

Accident Research Centre, Building 70, Clayton Campus, Wellington Road, Clayton, Victoria, Clayton, Victoria
3168, Australia

Correspondence to: Dr Finch, PHRDC Research Fellow.
On 1 July 1990 legislation was passed in Victoria making it compulsory for bicyclists of all ages to wear an approved helmet. Before mandatory bicycle helmet use, observational surveys had indicated low wearing rates in all age groups. In May/June 1990, just before the introduction of the law, these rates were estimated to be $65 \%$ in children (5-11 year olds), $21 \%$ in teenagers (12-17 years), and $36 \%$ in adults. ${ }^{1}$ As these were voluntary wearing rates, the rate among children was considered to be quite high.

Post-law helmet wearing surveys in 1991, one year after the introduction of mandatory wearing, found that helmet wearing rates were $78 \%$ in children, $45 \%$ in teenagers, and $74 \%$ in adults. By 1992, rates were $77 \%$ in children, $59 \%$ in teenagers, and $84 \%$ in adults. ${ }^{1}$ The increase in helmet wearing rates also correlated with a post-law reduction in severely injured bicyclists sustaining head injuries across all age groups. ${ }^{1}$

School education programs are promoted because they can have an important influence on bicycle safety behaviours in children. However, despite the fact that these have been promoted since the early 1980s, and the introduction of mandatory helmet wearing in Victoria, helmet wearing rates in 12-17 year olds remain considerably lower than in other age groups. This problem was also recently highlighted in this journal in a review of educational and legislative strategies used to promote helmet wearing. ${ }^{2}$ Observational surveys of bicycle usage have shown that both the number of bicyclists and the amount of bicycle exposure time decreased after the introduction of the law particularly in teenagers. ${ }^{1}$ Although teenage bicycle use rose between 1991 and 1992, it remained at below pre-law levels. Reasons for these trends in teenagers are currently unclear. Their attitudes towards helmet use may hold the answer.

\section{Methods}

For the purposes of this study, a teenager was defined to be an individual aged between 13 and 17 years and in year 9 or year 10 at a secondary school.

A total of 20 state secondary schools from Melbourne's outer south eastern suburbs were approached to participate in this survey. Of these, 12 agreed to participate, two did not agree, and the remainder did not respond to the initial application. Two other schools (one private) were also invited to participate in the study. The study was, therefore, conducted in 13 state schools and one private school. Children attending these schools typically come from lower to middle income families. The responses from the private school students did not 
differ from those from the state schools. All students of selected year 9 and 10 classes who attended each school during the last week of semester 3 (September) 1993 participated in the study. The survey was completed under class supervision and all students required to complete it. All responses were anonymous and there was a $100 \%$ response rate.

The schools that were invited to participate were identified by VIC ROADS on the basis that they had purchased the school's bicycle safety education resource materials in the previous year and should therefore, have had some form of bicycle education program in place. While it is recognised that this selection criterion would not necessarily lead to schools representative of the whole area, it was considered that valuable information could still be obtained from these students. Information was not obtained from the schools about the extent of the education programs they were coordinating at the time of the survey. This limitation may also limit the extent to which the study results can be generalised.

A self report questionnaire was developed to collect information about teenagers' attitudes, behaviours, and knowledge towards bicycle helmets and bicycle usage. This questionnaire was administered to a group of year 9 and year 10 students who attended school during the last week of semester 3, 1993. Closed questions with specified options were generally used to facilitate analysis. Open ended questions were also used to more fully explore attitudes and behaviours.

The questionnaire collected information about: (i) basic demographics, (ii) frequency of bicycle use, (iii) helmet ownership and wearing patterns, including factors affecting wearing and bicycle use (such as helmet type); (iv) attitudes towards helmet wearing, and (v) perceived injury vulnerability. All attitudinal data was precoded before computer entry onto a PC. Descriptive statistical analyses were performed with the SPSSWIN statistical package.

A total of 1268 completed questionnaires were received from the 14 participating schools. A small number $(n=28)$ of responders gave their age as outside the 13-17 year range (defined as teenagers in this study) and so have been excluded from the results presented here. No other questionnaires were excluded or considered illegible or unusable. The results, therefore, correspond to the 1240 teenagers aged 13-17 years who responded to the survey.

\section{Results}

DEMOGRAPHICS

Of the 1234 students who provided information about their year level at school, $53.1 \%$ were in year 9 and $46.9 \%$ in year 10 . The majority of students $(94.9 \%)$ were aged between 14 and 16 years, with a modal age of 15 years. Males and females were equally represented in the sample (males $=616$, females $=612$, unknown $=12$ ). Only $6 \cdot 2 \%$ $(n=77)$ of the teenagers reported that they had participated in a bicycle education program during 1993.

FREQUENCY AND PATTERNS OF BICYCLE USE In Melbourne, the local weather is generally suitable for bicycling in September. During the two weeks before the survey, $74.8 \%$ of males but only $34.5 \%$ of females reported that they had ridden a bicycle. The proportion of teenagers who reported that they do not ride a bicycle was higher in females $(10.9 \%)$ than males $(2 \cdot 8 \%)$.

Information was also obtained about where teenagers rode their bicycles. The most common places for riding a bicycle were 'to go to the shops' $(47 \cdot 3 \%)$ or 'to go to a friend's house' $(42 \cdot 8 \%)$. Males were four times more likely to report that they rode a bicycle when they were 'out with their friends' than females. They were also more likely to ride a bicycle to and from school (28.4\% of males compared with $4.6 \%$ of females). Only $10 \cdot 2 \%$ said that they would not ride a bicycle because they did not have a helmet.

\section{HELMET OWNERSHIP AND WEARING PATTERNS}

Sixty nine per cent of teenagers who had ridden a bicycle in the past year reported that they owned a helmet, compared with $45 \%$ of the non-riders during this period.

Information was sought about the types of helmet worn to determine whether this was related to teenagers' attitudes about helmets. Females were more likely than males to own a helmet that consisted of foam and a thick layer of plastic $(85.5 \% v 49.4 \%$, respectively). Foam only helmets were more commonly owned by males $(24.0 \%)$ than females $(15.0 \%)$. Microshell helmets were also more common among males $(26.7 \%)$ than females $(19.5 \%)$. There was little difference in the proportion of teenagers who always wore a helmet according to helmet type.

More than half of all teenagers reported that they were happy with their helmet. However, this varied with the type of helmet. Forty nine per cent of those with a foam and a thick layer of plastic helmet were happy with it, compared with $51.9 \%$ of those with a microshell helmet, and $74.8 \%$ of those with a foam only helmet.

Over one third of all teenagers stated that they wore a bicycle helmet the last time they rode a bicycle. The proportions of teenagers reporting that they always wore a helmet when riding a bicycle was $23.8 \% ; 19.8 \%$ said they wore one most of the time, $17 \cdot 3 \%$ wore one some of the time, and $39.1 \%$ never, or hardly ever, wore one.

\section{FACTORS ASSOCIATED WITH HELMET}

WEARING

The students were asked to state whether a person should always wear a helmet under specified circumstances (table 1). Females reported that people should wear their helmets in all circumstances more frequently that did 
Table 1 Circumstances under which teenagers believe people should always wear a helmet when they ride a bicycle; values are per cent

\begin{tabular}{llll}
\hline Circumstance & $\begin{array}{l}\text { Males } \\
(n=616)\end{array}$ & $\begin{array}{l}\text { Females } \\
(n=612)\end{array}$ & $\begin{array}{l}\text { All } \\
(n=1240)\end{array}$ \\
\hline On a main road & $74 \cdot 8$ & $92 \cdot 8$ & $83 \cdot 8$ \\
On a quiet back street & $29 \cdot 2$ & $45 \cdot 3$ & $37 \cdot 0$ \\
On a footpath & $34 \cdot 9$ & $57 \cdot 5$ & $46 \cdot 1$ \\
At home & $17 \cdot 7$ & $28 \cdot 8$ & $23 \cdot 2$ \\
On a path or track & $34 \cdot 1$ & $55 \cdot 4$ & $44 \cdot 6$ \\
\hline
\end{tabular}

$\star$ Sex of 12 teenagers was unknown.

males. However, both groups appear to regard all areas, other than a main road, as areas of 'low risk' and therefore considered the need to wear a helmet to be low.

ATTITUDES TOWARDS HELMET WEARING Attitudes towards bicycle helmets were sought by asking 'when you do not wear a helmet, what are the reasons?', 'what reasons would make you wear a helmet?', and 'should bicycle helmets be improved?'

Table 2 lists the most commonly given reasons for not wearing a helmet and the most common reason was finding the helmet uncomfortable. A significant proportion $(16.2 \%)$ stated that they would not wear one if they did not need to, for example, when they were riding at home, on their street, or in a place not considered by them to be dangerous. Other reasons given by few students included 'I am safe without one', 'it confines my hair', and 'I am only going for a short ride'. There was no relationship between the reasons for not wearing a helmet and the helmet type.

The major reasons stated for wearing helmets are given in table 3 . Over half of all teenagers, particularly females, stated that they would wear helmets to be safe. Fear of the police or the possibility of receiving a fine for not wearing a helmet was an important reason for wearing in only $14.9 \%$ of cases, despite a relatively moderate level of enforcement. ${ }^{1}$ Other reasons for wearing helmets stated by some respondents were 'when other people make me wear one', 'when I am not riding a short distance', and 'when the terrain is difficult'.

Just under one third of all teenagers felt that the currently available helmets did not need to be improved (table 4). A significant proportion who felt that helmets could be improved could not give specific suggestions how this could be achieved. Of some interest was the response by $4 \%$ that teenagers' attitudes towards helmets

Table 2 Reasons why teenagers do not wear a bicycle helmet; values are per cent

\begin{tabular}{|c|c|c|c|}
\hline Reasons cited by teenagers & $\begin{array}{l}\text { Males } \\
(n=616)\end{array}$ & $\begin{array}{l}\text { Females } \\
(n=612)\end{array}$ & $\begin{array}{l}A l l^{\star} \\
(n=1240)\end{array}$ \\
\hline I find it uncomfortable/annoying & $30 \cdot 8$ & $35 \cdot 9$ & $33 \cdot 5$ \\
\hline It's not fashionable & $22 \cdot 2$ & 23.9 & $23 \cdot 0$ \\
\hline $\begin{array}{l}\text { When I forget it or do not have one or cannot } \\
\text { afford one }\end{array}$ & $14 \cdot 1$ & $11 \cdot 9$ & $13 \cdot 1$ \\
\hline I dislike them & $12 \cdot 3$ & $9 \cdot 8$ & $11 \cdot 0$ \\
\hline I only ride at home or on my street & $6 \cdot 2$ & $12 \cdot 3$ & $9 \cdot 1$ \\
\hline $\begin{array}{l}\text { When it is not needed because I am not riding } \\
\text { in a dangerous place }\end{array}$ & $5 \cdot 7$ & $8 \cdot 7$ & $7 \cdot 1$ \\
\hline
\end{tabular}

^Sex of 12 teenagers was unknown. needed to be improved. Other responses included 'they should be stronger and withstand more than one impact', 'they should be cheaper', and 'they should be more protective'.

Some of the suggestions for improving bicycle helmets varied according to the type of helmet owned. Fewer owners of foam and a thick layer of plastic helmets thought that they were 'OK' $(28.4 \%)$ and did not need changing compared with owners of other types of helmets $(39.3 \%)$. Owners of foam and a thick layer of plastic helmets were also more likely to state that they needed to be made more comfortable and/or lighter $(20.9 \% v 10.8 \%$ for other types of helmet).

\section{PERCEIVED INJURY VULNERABILITY}

Table 5 summarises the teenagers' perceived injury vulnerability during hypothetical incidents. These results indicate that teenagers' perceive the risk of a severe injury (for example one resulting in death or brain damage) to be greatly reduced if a helmet is worn. Furthermore, the risk of injury from a collision with a car or truck is perceived to be greater than a non-collision fall from a bicycle.

\section{Discussion}

Unfortunately, there have been few published studies of the attitudes of teenagers', rather than younger children, towards bicycle helmets. Joshi et al conducted a survey of 655 bicyclists aged 14-18 years from four large secondary schools in Oxford. ${ }^{3}$ These teenagers believed that helmets would reduce the risk of severe injury (96\%) and thought they ought to wear one. However, $71 \%$ reported that helmets looked ridiculous and $81 \%$ felt that they were hot and uncomfortable.

In communities without bicycle helmet legislation, children view helmets as smart or safe but may not wear them because they are 'uncool' or associated with parental discipline ${ }^{45}$ Howland et al found that a misperception of peer attitudes is a major barrier in primary schoolchildren. ${ }^{4}$ Although students thought that they may be inviting derision from their peers if they wore a helmet, they tended to respect other children who did. Peer pressure has also been identified in other studies as one of the major factors leading to low helmet wearing rates. ${ }^{6-10}$

Pendergast et al found that sibling helmet ownership, parental helmet use, cost, and lower parental perceived social barriers to helmet use were independently associated with students' reported helmet use. ${ }^{11}$ Other studies have identified parental influence, ${ }^{69}$ perceived lack of need, ${ }^{710}$ appearance, and comfort as other important factors. ${ }^{410}$ DiGuiseppi et al also found that students who rode on streets were less likely than those who used parks or bicycle parks to wear helmets because of their perceived lack of risk. ${ }^{6}$

The study reported here found that approximately $94 \%$ of teenagers had not taken part in a bicycle education program in the past year, despite their school having available resource 
Table 3 Reasons why teenagers would wear a bicycle helmet; values are per cent

\begin{tabular}{llll}
\hline $\begin{array}{l}\text { Reasons cited by } \\
\text { teenagers }\end{array}$ & $\begin{array}{l}\text { Males } \\
(n=616)\end{array}$ & $\begin{array}{l}\text { Females } \\
(n=612)\end{array}$ & $\begin{array}{l}\text { Al } \\
(n=1240)\end{array}$ \\
\hline I want to be safe & 44.0 & 64.1 & 53.9 \\
My parents make me & 26.9 & 36.4 & 31.5 \\
Due to the law/police & 7.5 & 8.2 & 7.8 \\
force & 7.8 & 6.4 & $7 \cdot 1$ \\
I don't want a fine & 7.8 & & \\
\hline
\end{tabular}

^Sex of 12 teenagers was unknown.

materials. Schools purchase bicycle education material for various reasons. Some include it into the curriculum whereas others may use it for resource material only. Many schools restrict formal bicycle education programs to years 7 and 8, and any programs in years 9 and 10 would probably be as an elective in physical education or outdoor education, or be part of an after school hours training program for special bicycling events. Nevertheless, nonattendance at a recent education program may be a contributing factor to the lack of safety knowledge demonstrated by some respondents. It is likely, however, that the year 9 and 10 students would have been exposed to bicycle safety education sometime in the three years since the law was passed.

Despite so few respondents having taken part in a recent education program, most appear familiar with the importance of bicycle helmets as a safety measure. The important problem areas identified in this survey are low helmet ownership and wearing rates; the low priority teenagers place on safety compared with comfort and peer acceptance; and an ignorance of the need for helmets in all riding situations.

More than half of the teenagers had ridden a bicycle in the two weeks before the survey demonstrating that riding a bicycle is a popular activity for this age group. Some teenagers reported that they had also used other forms of wheeled transport, such as off-road motorbikes $(16.4 \%)$, skateboards $(15.9 \%)$, in-line skates $(12 \cdot 3 \%)$. Compared with the usage rates for

Table 4 Teenagers' suggestions for improving bicycle helmets; values are per cent

\begin{tabular}{|c|c|c|c|}
\hline Suggestions & $\begin{array}{l}\text { Males } \\
(n=616)\end{array}$ & $\begin{array}{l}\text { Females } \\
(n=612)\end{array}$ & $\begin{array}{l}A l l^{\star} \\
(n=1240)\end{array}$ \\
\hline $\begin{array}{l}\text { No change. I think that they are all right now } \\
\text { They should be made more confortable and/or } \\
\text { lighter }\end{array}$ & $\begin{array}{l}37 \cdot 7 \\
11 \cdot 9\end{array}$ & $\begin{array}{l}26 \cdot 1 \\
18 \cdot 5\end{array}$ & $\begin{array}{l}31 \cdot 9 \\
15 \cdot 1\end{array}$ \\
\hline $\begin{array}{l}\text { They should be changed (but no specific } \\
\text { suggestion given) }\end{array}$ & $11 \cdot 0$ & $18 \cdot 0$ & $14 \cdot 4$ \\
\hline $\begin{array}{l}\text { Their appearance and colour should be improved } \\
\text { Teenagers' attitudes need to be improved }\end{array}$ & $\begin{array}{r}10 \cdot 1 \\
3 \cdot 9\end{array}$ & $\begin{array}{r}17 \cdot 2 \\
3 \cdot 9\end{array}$ & $\begin{array}{r}13 \cdot 5 \\
3.9\end{array}$ \\
\hline
\end{tabular}

$\star$ Sex of 12 teenagers was unknown. other modes of wheeled recreation or self transport, bicycling is still the most popular of the options available to this age group.

Of all teenagers $65 \%$ reported that they owned a bicycle helmet. This is consistent with the helmet ownership rate established during the 1992 survey in Melbourne. ${ }^{1}$ However, less than $25 \%$ of all teenagers reported always wearing a helmet, despite the fact that this is compulsory by law.

Appearance and comfort were the most important factors influencing acceptability. This observation is supported by the fact that among the suggested improvements, those affecting improvements to their appearance and comfort were the most common. There was little difference in the proportion of teenagers who always wore a helmet according to helmet type. This suggests that factors other than helmet design are also important in determining whether or not a teenager wears a helmet.

Safety was also a major consideration when choosing to wear a helmet, as was parental influences. Many teenagers feel that people do not need to wear a helmet in many of the areas where they bicycle regularly. For example, while $27 \%$ of teenagers ride their bicycles on a path or track, less than half feel that a helmet is necessary in this environment.

Respondents believed that hitting a vehicle is more dangerous than just falling off a bicycle, and that there are dramatic decreases in the likelihood of brain damage and death when helmets are worn. This serves to emphasise how powerful poor social acceptance and poor comfort are as deterrents to helmet use, given that teenagers know they should wear helmets, yet so many do not. In Victoria, driving learners permits are not issued to persons under 17 years of age. This means that driver education does not have an impact on the perception of risk associated with motor vehicles in relation to bicycling among the age group considered here.

\section{Implications for prevention}

This study provides valuable information about teenagers' attitudes towards bicycle helmets after mandatory helmet wearing has been established for three years. The results presented here indicate that teenagers do not believe that the helmet legislation has affected their behaviour. Nevertheless, the large relative increase in helmet wearing in this age group since the law suggests that the legislation may be acting indirectly, for example by getting their parents to insist on them wearing helmets.

The present study also provides evidence to suggest that further interventions must be

Table 5 Teenagers' beliefs about the worst thing that could happen to a cyclist under different scenarios; values are per cent

\begin{tabular}{|c|c|c|c|c|c|c|}
\hline \multirow[b]{2}{*}{ Scenario } & \multicolumn{6}{|c|}{ Worst thing that could happen to the respondent under the following scenarios } \\
\hline & No & Nothing & $\begin{array}{l}\text { Scrapes, cuts, } \\
\text { bruises }\end{array}$ & Broken bones & Brain damage & Killed \\
\hline $\begin{array}{l}\text { Fall from bicycle and you were not wearing a helmet } \\
\text { Fall from bicycle and you were wearing a helmet } \\
\text { Knocked over by a car or truck and you were wearing a helmet } \\
\text { Knocked over by a car or truck and you were not wearing a helmet }\end{array}$ & $\begin{array}{l}1202 \\
1202 \\
1205 \\
1205\end{array}$ & $\begin{array}{l}5 \cdot 1 \\
5 \cdot 4 \\
1 \cdot 8 \\
3 \cdot 7\end{array}$ & $\begin{array}{r}12 \cdot 4 \\
26 \cdot 5 \\
2 \cdot 6 \\
0 \cdot 4\end{array}$ & $\begin{array}{r}8 \cdot 9 \\
38 \cdot 0 \\
31 \cdot 0 \\
3 \cdot 0\end{array}$ & $\begin{array}{r}18 \cdot 1 \\
6 \cdot 1 \\
9 \cdot 1 \\
6 \cdot 4\end{array}$ & $\begin{array}{l}52 \cdot 5 \\
22 \cdot 9 \\
52 \cdot 7 \\
83 \cdot 8\end{array}$ \\
\hline
\end{tabular}


designed and investigated to further increase helmet wearing rates, even after helmet wearing rates have increased and legislation has been implemented. This is particularly important for teenage bicyclists.

Future education programs should emphasise that helmets should be worn whenever a bicycle is ridden, not just in traffic or other obviously dangerous situations. Parents should also continue to encourage their teenagers to wear bicycle helmets. Education programs aimed at adults' awareness of bicycle safety issues could also be promoted to increase the number of parents who demand helmets be worn by their children and provide role models for teenagers. Given that changing behaviours in teenagers is difficult, the best long term solution would be to target education at young children to adopt a life long habit of helmet use, before they become teenagers.

Helmet manufacturers and government bodies could help by promoting the availability of modern, light, well ventilated, and stylish helmets. Teenagers are more likely to be happy about wearing such helmets and their availability would help parents encourage helmet wearing by their children.

Finally, this study has also raised enforcement as a factor in helmet wearing behaviours under a legislative system, even in a community with a relatively moderate level of enforcement. Only $15 \%$ of teenagers cited the possibility of receiving a fine or enforcement of the mandatory helmet wearing law by the police as a reason for wearing a bicycle helmet. This suggests that teenagers do not consider the issuing of a fine or police enforcement as either likely or serious. The possibility of a fine being imposed on non-helmet wearing bicyclists should be emphasised and enforced by the relevant authorities. The perception that fines are low and unlikely to be incurred should also be addressed.

Dr Caroline Finch was partially funded by a PHRDC (Public Health Research and Development Committee) Research Fellowship. The survey was administered and coordinated by third year health promotion students (Jason Ferla, Georgina Chin, Patrick Maloney, Pooma Abeysiri) as a research project for their course, supervised by Dr Finch. Analysis of the survey data was course, supervised by Dr Finch. Analysis of the survey data was staff are gratefully thanked for their participation in the study.

1 Cameron $\mathrm{MH}$, Vulcan AP, Finch CF, Newstead SV. Mandatory bicycle helmet use following a decade of helmet promotion in Victoria, Australia - an evaluation. Accid Anal Prev 1994; 26: 325-37.

2 Graitcer PL, Kellerman AL, Christoffel T. A review of educational and legislative strategies to promote bicycle helmets. Injury Prevention 1995; 1: 122-9.

3 Joshi MS, Beckett K, Macfarlane A. Cycle helmet wearing in teenagers - do health beliefs influence behaviour? Arch Dis Child 1994; 71: 536-9.

4 Howland J, Sargent J, Weitzman M, et al. Barriers to bicycle helmet use among children. Results of focus groups with helmet use among children. Results of focus groups with fourth,

5 Bergman AB, Rivara FP, Richards DD, Rogers LW. The Seattle children's bicycle helmet campaign. Am $f$ Dis Child 1990; 144: 727-31

6 DiGuiseppi CG, Rivara FP, Koepsell TD, Polissar L. Bicycle helmet use by children. Evaluation of a community-wide helmet campaign. $\mathcal{F} A M A 1989 ; 262$ 2256-61.

7 DiGuiseppi CG, Rivara FP, Koepsell TD. Attitudes towards bicycle helmet ownership and use by school-age children. Am $\mathcal{F}$ Dis Child 1990; 144: 83-6.

8 Otis I, Lesage D Godlin G, Brown B, Farley C Lambert J. Predicting and reinforcing children's intentions to wear protective helmets while bicycling. Public Health Rep 1992; 107: 283-9.

9 Dannerberg A, Gielen A, Beilenson P, Wilson M, Joffe A. Bicycle helmet laws and educational campaigns: an evaluation of strategies to increase children's helmet use. Am f Public Health 1993; 83: 667-73.

10 Seijts GHP, Koh G, Bouter LM, Klip HAJ. Barriers to wearing bicycle safety helmets in the Netherlands. Arch Pediatr Adolesc Med 1995; 149: 174-80.

11 Pendergast RA, Ashworth CS, DuRant RH, Litaker M Correlates of children's bicycle helmet use and short-term failure of school-level interventions. Pediatrics 1992; 90: 345-58

\section{Insist on an electrical inspection}

It pays to have an electrical inspection to ensure that any electrical work done in your home or workplace meets the Safety Code. Most inspectors are highly qualified and can help by answering questions or providing valuable safety tips. Insist on an inspection if:

- You've had any wiring done for a renovation

- You've added a swimming pool or garage

- You've installed a new furnace or central air conditioning

- You've put in new appliances requiring electrical connections

- You've had or are having your electrical service upgraded.

Remember, having an electrical inspection is for your safety, peace of mind, and it's required by law.

\section{Choosing safe child care}

Recently a coroner's inquest was held into the death of a 13 month old who was in the care of a homecare provider. She had been put down for a nap in a playpen in a closed room without a monitor and strangled on a broken hinge on the outside of the playpen while attempting to climb out. One of the coroner's jury recommendations was that 'Above all, parent awareness is the most important deciding factor when choosing a caregiver. The availability of this information should be a major priority'. But what safety issues do our readers think parents should look for when choosing child care? 